\title{
Characterizing a novel predator-prey relationship between native Diplonychus esakii (Heteroptera: Belostomatidae) and invasive Gambusia affinis (Teleostei: Poeciliidae) in central China
}

\author{
Xu Ouyang $\cdot$ Jiancao Gao $\cdot$ Bojian Chen $\cdot$ Zaizhao Wang $\cdot$ \\ Hong Ji $\cdot$ Martin Plath
}

Received: 22 September 2016/Accepted: 1 April 2017/Published online: 11 April 2017

(C) The Author(s) 2017. This article is an open access publication

\begin{abstract}
A considerable body of the literature considers the potential impact of exotic predators on native prey organisms, while comparatively, few studies have asked whether and how native predators include novel prey types into their diet spectrum. Here, we asked whether the native aquatic heteropteran Diplonychus esakii preys on the highly invasive western mosquitofish (Gambusia affinis), which has been introduced to southern China and threatens native fish species through competition and predation on their fry. We conducted 48-h prey choice experiments under semi-natural conditions. In a 'no-choice' experiment (one predator and one potential prey; $n=200$ ), we found the heteropterans to prey more on large-bodied fish, a pattern that was also described for other belostomatids, while prey sex had no effect on capture rates. Moreover, large-bodied heteropterans caught more fish than small-bodied individuals. However, overall capture rates in our study were low (11.5-30\%) compared to studies on other belostomatids, which explains why subsequent binary prey choice experiments using one predator and two prey-either large and small females or male and female (with smaller sample sizes of $n=20$ and 30, respectively) — did not confirm the results of our first experiment. Our study exemplifies how a pattern of body size-dependent predation can arise in a novel (not coevolved) predator-prey interaction. We tentatively argue that the observed pattern could be driven by intrinsic features of the predator, namely, altered prey preferences with increasing age coupled with a general preference for large-bodied prey, or changing nutritional needs at different developmental stages.
\end{abstract}

Keywords Aquatic invasion $\cdot$ Mosquitofish $\cdot$ Neozoan $\cdot$ Predator-prey interaction

\section{Introduction}

Biological invasions challenge the conservation of native biodiversity and can have profound impacts on ecological processes and evolutionary dynamics (Gurevitch and Padilla 2004; Kistner and Dybdahl 2013; Stuart et al. 2014). Several studies focused on the question of whether and how invasive predators affect native prey species (Gerard et al. 2014; Nunes et al. 2014). For example, predation experiments by Błońska et al. (2015) demonstrated that the Ponto-Caspian racer goby Babka gymnotrachelus preys more on the native

X. Ouyang $\cdot$ J. Gao $\cdot$ B. Chen $\cdot$ Z. Wang $\cdot$ H. Ji $\cdot$ M. Plath

College of Animal Science and Technology, Northwest A\&F University, Yangling 712100, Shaanxi,

People's Republic of China

M. Plath $(\bowtie)$

Department of Ecology and Evolution, Goethe University Frankfurt, Max-von-Laue-Straße 13, 60438 Frankfurt am Main, Germany

e-mail: mplath-zoology@gmx.de 
amphipod Gammarus fossarum than invasive Dikerogammarus villosus and Pontogammarus robustoides in its invasive range in Poland. Fewer studies have asked how invasive prey species integrate into existing food webs (e.g., Weerman et al. 2014; Cabrera-Guzmán et al. 2015; Raspi et al. 2015). One important step towards understanding trophic relationships between native predators and invasive prey species is to examine predators' feeding preferences, for instance, via standardized food choice experiments (see Horstkotte and Plath 2008; Plath et al. 2011).

Our present study provides insights into a novel predator-prey interaction between the predatory aquatic heteropteran Diplonychus cf. esakii and invasive western mosquitofish (Gambusia affinis) in central China. The members of the family Belostomatidae (Heteroptera: Hemiptera; giant water bugs) are voracious sit-andwait predators with extra-oral digestion that prey on a variety of invertebrates and vertebrates (Menke 1979). They are typically found sitting along the water's edge posing with their front legs below and their abdominal spiracles above the water surface, from where they catch bypassing prey with their raptorial forelegs that are strongly incrassate, with the femora often grooved to accept the tibiae (Menke 1979). Upon capture, belostomatids inject toxins causing prey paralysis and digestive enzymes causing tissue necrosis (Swart and Felgenhauer 2003; Swart et al. 2006).

While the large-bodied members of the subfamily Lethocerinae feed on small snakes, anurans, and fish, the much smaller members of the subfamily Belostomatinae mainly feed on various invertebrates and anuran larvae, but do not regularly prey on fish (Cullen 1969; Babbitt and Jordan 1996; Swart and Felgenhauer 2003; Mori and Ohba 2004; Ohba and Nakasuji 2006; Swart et al. 2006; Ohba 2011). Prey selection in belostomatines has been thoroughly investigated in the predator-prey relationship between Belostoma cf. bakeri and a co-occurring fish, the cave molly (Poecilia mexicana) in a South-Mexican sulfur cave. Due to the toxic effects of hydrogen sulfide $\left(\mathrm{H}_{2} \mathrm{~S}\right)$ and the associated extreme hypoxia in the water, cave mollies must spent considerable time performing aquatic surface respiration (Plath et al. 2007), rendering them vulnerable to attacks by giant water bugs (Tobler et al. 2009). Prey choice experiments found the heteropterans to preferentially prey upon large-bodied fish (Plath et al. 2003; Tobler et al. 2007), and to prefer gestating over non-gestating females (Plath et al. 2011), and males over females (Tobler et al. 2008). While higher predation risk of largebodied fish could be explained by better (non-visual) detectability of surfacing large-bodied individuals, higher predation on males and gestating females is likely a function of increased energy demands of males and gestating females, leading to increased aquatic surface respiration and, thus, increase likelihood of falling victim to heteropteran predators (Tobler et al. 2008; Plath et al. 2011).

In contrast to the aforementioned system involving coevolved predatory and prey species, our current study focused on a novel predator-prey relationship between the belostomatine D. esakii and their potential exotic prey, Western mosquitofish, Gambusia affinis (like P. mexicana, a member of the neotropical family Poeciliidae). Since its introduction to China in 1927 for malaria prophylaxis, G. affinis has spread widely in the Yangtze River drainage (Li and Xie 2002). Studies on interspecific ecological relationships between invasive G. affinis and native fish species, such as Tanichthys albonubes and Oryzias latipes, suggest that G. affinis threatens the survival of these species (Chen et al. 1989; Chen 2010), highlighting the need for investigations into predation on invasive G. affinis by native faunal elements in China, and our present study represents a first step in this direction.

Our study was motivated by the observation that, while belostomatines do not usually prey on fish (see above), they occasionally seem to function even as top predators, e.g., in the aforementioned Mexican sulfur cave with unusually high densities of fish (mean \pm SE: $162.3 \pm 16.1$ individuals $\mathrm{m}^{-2}$; Jourdan et al. 2014) and B. bakeri (1.12 \pm 0.43 individuals $\mathrm{m}^{-2}$; Tobler et al. 2007). Moreover, a previous study found congeneric Diplonychus rusticus to prey on small fish under natural conditions (Hazarika and Goswami 2012). During field work, we repeatedly noted high densities of $D$. esakii (and other aquatic heteropterans) in several stagnant water bodies in China, in which the species regularly co-occurs with the abundant invasive G. affinisincluding the study site we chose for our present study (Fig. 1a). Therefore, we tested whether some common patterns of prey selection in the well-researched B. bakeri-P. mexicana predator-prey relationship (Plath and Tobler 2010) would also be apparent in the novel predator-prey interaction between D. esakii and G. affinis.

Using prey choice experiments under semi-natural conditions, we first experimentally confirmed the assumption that D. esakii prey on G. affinis, as previous studies found other belostomatines (including members of the genus Diplonychus) to include fish prey (Plath et al. 2003, 2011; Tobler et al. 2007, 2008, 2013; Hazarika and Goswami 2012). Having confirmed this assumption, (1) we then asked if a 

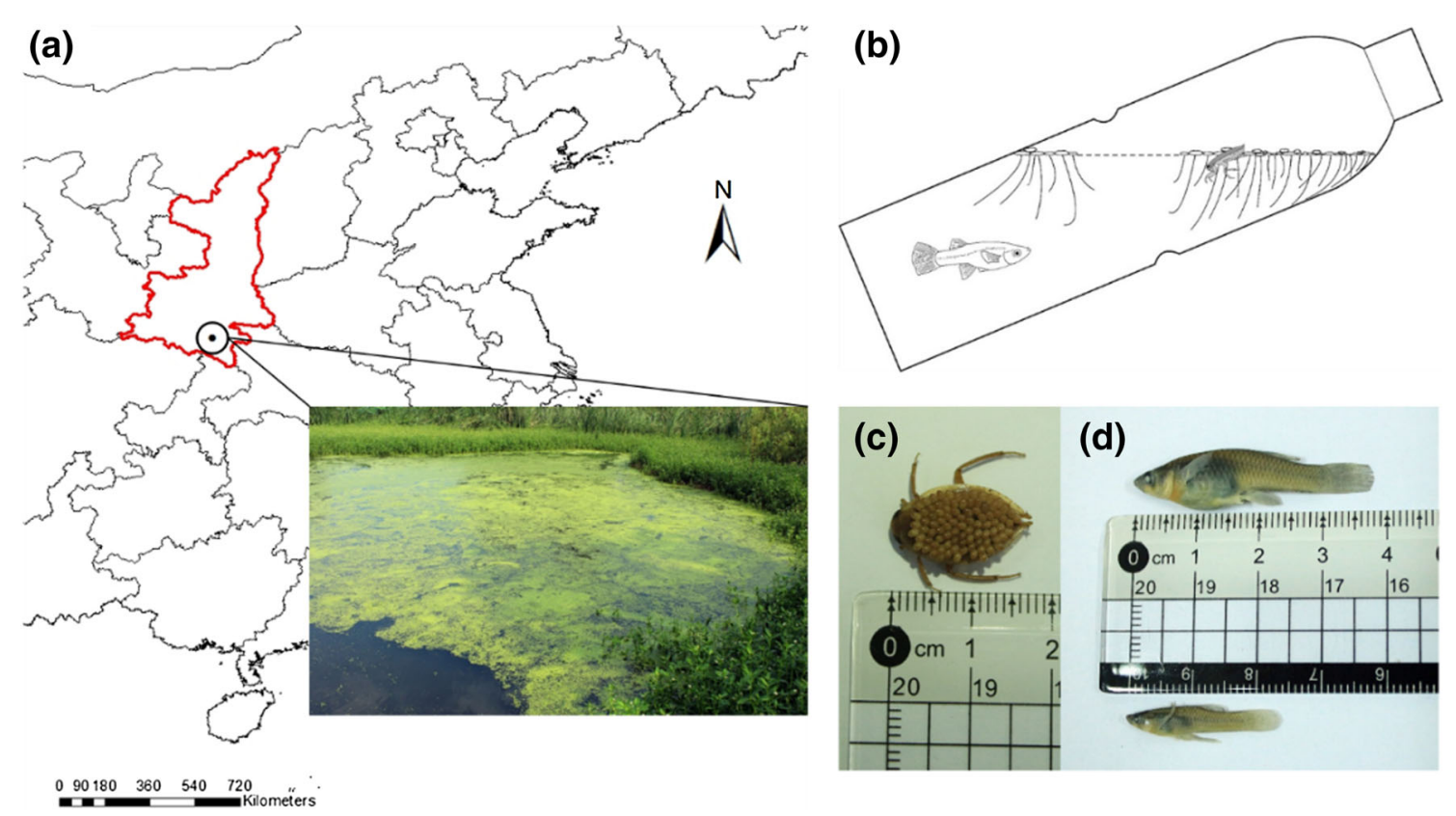

Fig. 1 Study site and exemplary photos of experimental test subjects. a Study site near Ankang in Shaanxi Province (highlighted) in central China. Insert shows the abandoned fish pond in which predation experiments were conducted. b Schematic view on an experimental unit containing one predator and one prey fish. c Adult male Diplonychus cf. esakii carrying a clutch on its abdomen; d adult female (above) and male Gambusia affinis (below) collected at our study site (photographs were taken from ethanolpreserved specimens)

pattern of size-specific predation exists. We predicted that D. esakii would show a predilection for larger over small-bodied mosquitofish, which would be congruent with optimal foraging theory (Pyke 1984). (2) As previous studies found male-biased predation by B. cf. bakeri on another poeciliid (Tobler et al. 2008), we predicted a similar pattern in the predatory interaction between D. esakii and G. affinis, as poeciliid males expose themselves more to predators during their continuous mate searching and mating behavior (Godin 1995). (3) Furthermore, we asked if the predators' body size would affect their prey selection (e.g., in the form of large-bodied predators preferring large prey items and small-bodied predators preferring smaller prey). This prediction was based on previous studies showing that different instar stages in belostomatids differ in metabolic rates and foraging tactics (Biesmeijer and Tóth 1998; Cloarec 1990).

\section{Materials and methods}

We conducted two types of experiments: (a) a 'no-choice' predation experiment (i.e., one predator and one prey fish per test run) used randomly assigned combinations of water bugs and mosquitofish to establish general patterns of body size- and sex-dependent predation. (b) In the latter experiment, we found large individuals to prey more on mosquitofish than small-bodied individuals (see "Results"); hence, we conducted binary prey choice experiments (i.e., one predator and two prey fish per test run) with only large-bodied (adult) D. esakii to verify the effect of prey body size (higher predation on large- compared to small-bodied fish), and we tested if an effect of prey sex (higher predation on male vs. female mosquitofish) might become apparent in this experimental situation.

\section{Study site}

We conducted our experiments between May 20th and August 25th 2015 in an abandoned fish pond located near the Aquaculture Demonstration Center of Northwest A\&F University, close to the national road G316 in 
Ankang, Shaanxi Province, China (E 108.807, N 32.73409; $222 \mathrm{~m}$ altitude). The pond was surrounded by dense riparian vegetation, and a large portion of the pond's surface was covered with floating filamentous green algae and duckweed (Lemna sp.; Fig. 1a).

We collected adult and juvenile $G$. affinis and D. esakii using dip nets ( $1 \mathrm{~mm}$ mesh size) and kept them separated by species in aerated buckets in the shade (for less than $1 \mathrm{~h}$ ) until they were used in one of the following experiments. We first checked all collected fish for signs of attacks from heteropteran predators (puncture wounds) and made sure that only fish without such wounds entered the experiments. Heteropterans collected for the prey choice experiments included males carrying clutches on their abdomen and individuals without clutches; however, reliably determining the sex and the exact developmental stages of all test subjects was not feasible under field conditions. We collected several heteropterans and stored them in $96 \%$ ethanol for later species identification in the laboratory. Following the descriptions and keys provided by Miyamoto and Lee (1966) and Ding (2004), the collected heteropterans were identified as Diplonychus cf. esakii, originally described from Chejudo, Korea.

We initially collected a larger number of $G$. affinis than needed in our prey choice experiments. We used the total sample of all collected fish to calculate the adult sex ratio (numbers of males/numbers of females) in our study population; this information was important for the discussion of our results on potential sex-specific predation. Fishes not used in the prey choice experiments were measured for the standard length (SL, from the tip of the snout to the posterior end of the caudal peduncle) so as to provide information on body size distribution patterns. Furthermore, to provide empirical data on population densities of D. esakii as mentioned in the "Introduction", we determined densities once (May 22nd, 2015) by counting larvae and adult water bugs (imagines) in six randomly selected $1 \times 1 \mathrm{~m}$ sampling squares along the edge of the pond through total counts.

Total counts of $D$. esakii in six randomly selected quadrants resulted in mean $( \pm \mathrm{SD})$ estimated densities of $2.5 \pm 1.9$ (1-6) adult individuals and $18.8 \pm 5.8$ (11-28) nymphs of different instar stages per square meter.

We collected $N=260 \mathrm{G}$. affinis in preparation of our no-choice experiment, which covered a wide range of body size $(6.2-39.6 \mathrm{~mm})$. Fifty-eight adult individuals were males (SL, mean $\pm \mathrm{SD}=16.41 \pm 1.40 \mathrm{~mm}$, range $=11.2-18.8 \mathrm{~mm})$, and 119 were females $(23.27 \pm 4.39 \mathrm{~mm}, 13.2-39.6 \mathrm{~mm})$. This resulted in an adult sex ratio of 0.49 . Amongst the inspected fish $(N=260)$, no cases of puncture wounds resulting from heteropteran attacks were observed.

We caught $N=232$ adult $G$. affinis in preparation of the binary prey choice experiments (this time leaving out juvenile fish). Ninety-six individuals were males $(\mathrm{SL}=19.90 \pm 1.98 \mathrm{~mm}$, range $=15.8-30.1 \mathrm{~mm})$ and 136 females $(32.49 \pm 3.46 \mathrm{~mm}, 22.9-39.9)$, and the adult sex ratio was 0.71 . Four female $G$. affinis had puncture wounds on their caudal peduncle (one per fish), presumably stemming from attacks by heteropterans or other predatory aquatic arthropods.

\section{Experimental setup}

\section{Control experiment}

Before we conducted our main experiments, we ran controls $(N=10$ replicates for the no-choice experiment with four cases of juveniles and equal numbers of males and females; $N=5$ replicates for the binary choice experiment with one male and one female per replicate) to assess baseline mortality and feasibility of our approach. We used experimental containers as described for our main experiments (see below) but did not introduce D. esakii, but only G. affinis and some floating vegetation. Standard lengths were $12.23 \pm 0.67 \mathrm{~mm}$ (11.5-12.8 mm; males), $35.50 \pm 3.86 \mathrm{~mm}$ (31.8-39.5 mm; females), and $8.90 \pm 1.35 \mathrm{~mm}$ (7.1-10.2 mm; juveniles) in the control runs of the no-choice experiment, and $20.60 \pm 3.43 \mathrm{~mm}$ (16.7-24.1 mm; males) and $33.84 \pm 5.93 \mathrm{~mm}(23.7-38.4 \mathrm{~mm}$; females) in the control runs of the binary choice experiments. No mortality was detected in any of the control runs after $48 \mathrm{~h}$. 
No-choice predation experiment

Our general experimental approach followed well-established protocols (Tobler et al. 2007; Plath et al. 2011). In the no-choice predation experiment $(N=200$ trials), a randomly selected individual of $G$. affinis $(\mathrm{SL}=16.67 \pm 6.12 \mathrm{~mm}$, size range $=6.2-31-0.5 \mathrm{~mm})$ as well as one individual of $D$. esakii (total length, $\mathrm{TL}=12.44 \pm 3.32 \mathrm{~mm}$, size range $=3.9-17.3 \mathrm{~mm}$ ) were introduced into each experimental container, a transparent plastic bottle $(600 \mathrm{ml})$. Some pieces of floating vegetation were added to provide opportunities for the water bugs to sit and prevent them from drowning (Fig. 1b). The bottles were perforated by 12 small holes to maintain water and oxygen exchange throughout the entire experiment. 20 bottles per batch were fixed in a PVC rack and then partially submerged near the edge of the pond and covered with riparian vegetation. A piece of green plastic net was placed between adjacent bottles to prevent visual contact between test subjects in different bottles.

Binary prey choice experiments

Our binary prey choice experiments largely followed the experimental approach described above, but we used only large-bodied (adult) heteropterans $(\mathrm{TL}=16.24 \pm 0.72 \mathrm{~mm}$, size range $=13.8-17.5 \mathrm{~mm}$ ) and offered two different mosquitofish in each experimental container. In the first experiment, we introduced one large $(\mathrm{SL}=37.32 \pm 1.13 \mathrm{~mm})$ and one small female mosquito fish $\left(29.92 \pm 2.39 \mathrm{~mm}\right.$; paired $t$ test: $t_{19}=14.01$, $p<0.0001$ ). The second experiment tested for sex-specific predation. We were unable to collect sufficient numbers of size-matched pairs of male and female G. affinis, as mosquitofish males are, on average, much smaller than females (Reznick 1981). Thus, we introduced one male $(20.27 \pm 1.07 \mathrm{~mm})$ and one small-bodied adult female mosquitofish $\left(32.17 \pm 2.08 \mathrm{~mm}\right.$; paired $t$ test: $\left.t_{29}=26.82, p<0.0001\right)$, while making an attempt to keep the size difference at a minimum.

The acclimation phase was kept short $(30 \mathrm{~min})$, because the total duration of our experiments $(48 \mathrm{~h})$ provided a sufficient time for all test subjects to settle and for the water bugs to exert predation. We terminated all tests after $48 \mathrm{~h}$ and screened the fish for signs of predation, as evidenced by puncture wounds (resulting from attempted attacks) or cases of mortality (i.e., successful attacks). In some cases, a partially lysed carcass was retrieved. All fish and heteropterans were measured for body size upon termination of a test (standard length, see above, in case of fish and total length, from the anterior tip of the head to the posterior tip of the abdomen, in case of the heteropterans).

\section{Statistical analysis}

Data from the no-choice experiment included juvenile mosquitofish (whose sex could not be determined) and adult fish. In a first analysis using only the subset of data involving adult fish ( $N=41$ males, $N=79$ females), we tested for an effect of prey sex on predation by D. esakii. We used 'predation success' (yes/no) as the dependent variable in a binary logistic regression with a stepwise backward elimination procedure (based on likelihood ratios) and coded 'predator body size' and 'prey body size' as covariates and 'prey sex' as a factor, including all two-way and three-way interactions. No sex effect was detected (see "Results"), and so we proceeded with an analysis that included all test runs (i.e., also juvenile mosquitofish) while excluding the factor 'sex' from the analysis. Finally, to corroborate both statistically significant effects of this analysis (see "Results"), we applied independent-samples $t$ tests to compare the body sizes of fish that were or were not preyed upon and D. esakii that did or did not catch fish.

When analyzing the results from the two binary prey choice experiments, we first asked what factors influence overall predation by $D$. esakii (i.e., independent of whether large/small or male/female fish were more preyed upon). We used 'predation success' (yes/no) as the dependent variable in binary logistic regressions while including the water bugs' body size as a covariate and 'presence of eggs' as a factor to test if males carrying a clutch would show lower capture rates (see Crowl and Alexander 1989 for predation by Belostoma flumineum on G. affinis). Note that 'presence of eggs' was not included in the previous analysis as a low number of $n=2$ males carrying eggs precluded inclusion of this factor. We also included the interaction term 'presence of eggs $\times$ body size' and excluded non-significant terms in a stepwise backward elimination 
procedure as mentioned above. Low capture rates (three out of 20 bottles, i.e., 15\%) in the experiment on sizedependent predation precluded further analysis of effects of prey body size, while sex-specific predation was evaluated for the subset of bottles in which predation had occurred by comparing observed frequencies of female and male predation against the distribution expected by chance using a $\chi^{2}$ test.

All data were analyzed using the SPSS statistical package (version 19, IBM) and are presented as mean \pm SD.

\section{Results}

No-choice predation experiment

Throughout our predation experiments, we observed only cases of predation by D. esakii on G. affinis, but not vice versa. In the no-choice experiment, predation by $D$. esakii occurred in $11.5 \%$ of cases (i.e., in 23 out of the $N=200$ independent replicates). Seven cases of predation involved male G. affinis, 14 female fish, and two cases juveniles. Our first binary logistic regression model using only the subset of sexually mature fish ( $-2 \log$ likelihood $=105.64$, Nagelkerke $R^{2}=0.08$ ) found neither 'sex' nor any interaction involving 'sex' to have statistically significant effects, and so they were excluded during the stepwise elimination procedure (Wald $<0.61, d f=1, p>0.30$ ).

In the model including both adult and immature mosquitofish $(-2 \log$ likelihood $=126.41$, Nagelkerke $R^{2}=0.15$ ), both covariates (SL of the mosquitofish: $B \pm \mathrm{SE}=0.11 \pm 0.04, \quad$ Wald $=7.81, d f=1$, $p=0.01$; TL of the heteropterans: $B \pm \mathrm{SE}=0.22 \pm 0.09$, Wald $=6.32, d f=1, p=0.01$ ) had significant effects and were retained during the stepwise elimination procedure, while all other factors and interactions were excluded (Wald $<0.01, d f=1, p>0.97$ ). To visualize both effects, we calculated residuals (differences between observed and predicted probabilities) for each covariate and plotted the resulting data against the respective other covariate (Fig. 2a, b).

Post hoc independent samples $t$ tests corroborated that fishes that were preyed upon $(20.24 \pm 4.91 \mathrm{~mm}$, range: $10.8-29.5 \mathrm{~mm}, N=23$ ) were significantly larger than those that were not preyed upon $\left(16.20 \pm 6.12 \mathrm{~mm}, 6.2-31.5 \mathrm{~mm}, N=177 ; t_{198}=3.04, p=0.003\right)$. Likewise, individuals of $D$. esakii that preyed on mosquito fish $(14.16 \pm 2.69 \mathrm{~mm}, 7.7-17.1 \mathrm{~mm})$ were significantly larger than their counterparts that did not $\left(12.21 \pm 3.34 \mathrm{~mm}, 3.9-17.3 \mathrm{~mm}, t_{198}=2.69, p=0.008\right)$.

Binary prey choice experiments

In our first binary prey choice experiment, we tested for size-specific predation on $G$. affinis females by $D$. esakii. Predation occurred in only three out of 20 bottles (15\%), whereby two of the three captured fish were small and one was large. This low overall predation rate precluded further statistical analysis of size-specific predation. In the final analytical model on overall capture success, only the covariate 'body size' of the water bugs was retained $(B \pm \mathrm{SE}=-0.11 \pm 0.04$, Wald $=7.75, d f=1, p=0.005)$. Diplonychus esakii that caught fish $(16.03 \pm 0.61 \mathrm{~mm}, N=3)$ were slightly smaller than those that did not catch any fish $(16.46 \pm 0.63 \mathrm{~mm}, N=17)$.

Our second binary prey choice experiment tested for sex-specific fish predation by $D$. esakii. Predation was twice as high as in our first binary prey choice experiment (i.e., nine out of 30 bottles, $30 \%$ ). Among the nine fish caught by $D$. esakii, a non-significant tendency was seen for higher predation on males (seven cases) than females (two cases; Chi-square test: $\chi^{2}=2.78, d f=1, p=0.096$ ). Again, only the covariate 'body size' had a statistically significant effect in the final model on overall capture success $(B \pm \mathrm{SE}=-0.06 \pm 0.03$, Wald $=4.85, d f=1, p=0.028)$, and water bugs that captured $G$. affinis $(15.68 \pm 0.94 \mathrm{~mm}, N=9)$ were again slightly smaller than those that did not $(16.29 \pm 0.51 \mathrm{~mm}, N=21)$. 

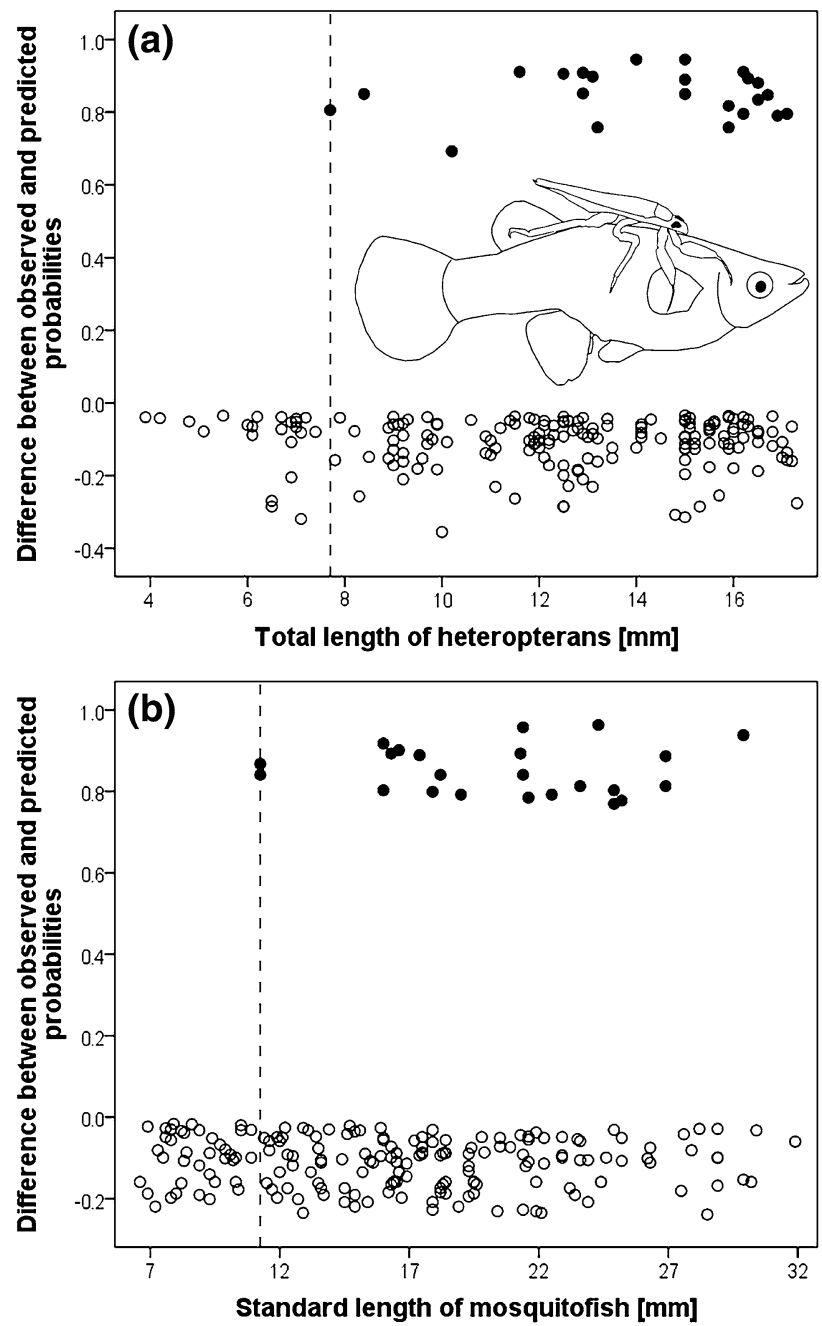

Fig. 2 Graphic illustration of the main effects in the multiple regression analysis on predation by the heteropteran D. cf. esakii on mosquitofish (G. affinis); a shows the effect of the heteropterans' body size (total length), while b shows the effect of prey body size (standard length). Depicted are residuals (difference between observed and predicted probabilities), whereby positive values and black circles indicate cases of successful predation, while negative values and open circles indicate no predation. Dotted lines indicate the minimum body size at which predation was observed (a: $7.70 \mathrm{~mm} ; \mathbf{b}: 10.80 \mathrm{~mm})$

\section{Discussion}

In the no-choice experiment, we cohabitated one individual of the aquatic heteropteran $D$. esakii with one individual of their potential exotic prey, the western mosquitofish (G. affinis). Gambusia affinis that were attacked were significantly larger than those that were not attacked, and D. esakii that preyed on G. affinis were themselves larger than those that did not. However, in this and in subsequent binary prey choice experiments, we found predation rates to be low (11.5-30\%). For comparison, when offering two differentsized Poecilia mexicana females as potential prey in a similar experimental design, predation rates by Belostoma cf. bakeri were as high as $44 \%$ (Tobler et al. 2007). Low predation rates in our present study likely explain why our subsequent binary choice experiments (with smaller sample sizes) did not corroborate an effect of prey body size. Only a non-significant tendency was seen for higher predation on males than on females. In contrast to our no-choice experiment, smaller $D$. esakii showed slightly higher overall predation than larger individuals in the binary choice experiments. Note, however, that we used only comparatively large-bodied (adult) predators in the binary choice experiments, such that our results are not necessarily conflicting (see below). Whether or not the relatively small dimensions of our experimental containers 
$(600 \mathrm{ml})$ played a role in affecting the outcome of our second experiment will need to be determined in future studies using larger containers (compare 1.5 L as used in Plath et al. 2011).

Our study corroborates predation by D. esakii on G. affinis and demonstrates that this exotic prey species is readily included into the prey spectrum of $D$. esakii. The overall low predation rate could be a result of both species not sharing a coevolutionary history, assuming that the predator does not adequately recognize its exotic prey (David et al. 2017), and D. esakii could evolve to be more efficient in the future (Carlsson et al. 2009). Another possible explanation for the low predation rate could be the short acclimation period. Stress resulting from mechanical handling affects individuals for different periods of time (Harak et al. 1998); however, we believe that this explanation is unlikely as the total duration of our tests was rather long (48 h). Some of the fish that we collected at our study site showed puncture wounds. However, some co-occurring aquatic insects (such as Ranatra cf. chinensis and Nepa cf. cinerea, both Nepidae) also prey on fish (Rao 1976; Bailey 1986), and so it remains to be determined whether or not D. esakii prey on mosquito fish not only in our experimental containers, but also in their natural environment. We are aware that fish prey certainly constitutes only a part of the total diet spectrum of $D$. esakii-as indicated by comparatively low overall predation rates-and so several points in our discussion will benefit from future experiments offering different types of invertebrate prey as well. For example, mosquito larvae (Culicidae) are a common prey type of giant water bugs and other aquatic heteropterans, and recent studies even recommended using belostomatids as new biological control agents of mosquitoes, i.e., for malaria control (Mukherjee and Datta 1999; Saha et al. 2010, 2014).

Using prey choice experiments involving individuals of the comparatively large-sized Lethocerus americanus (Lethocerinae), as well as three juvenile (small) and three adult (large) G. affinis, Schumann et al. (2012) found giant water bugs to preferentially prey on adult mosquitofish, characterizing the species as a specialized predator of adult fish. In our present study, we also detected a pattern of body size-dependent predation (question 1). Our finding of D. esakii preying more on larger G. affinis is congruent with optimal foraging theory (Stephens et al. 2007), whereby individuals accept opportunity and energetic costs of (potentially unsuccessful) attacks only when the expected benefits (in terms of net energy uptake) are high. Indeed, both male and female G. affinis showed pronounced variation in body size, which is congruent with studies from the species' natural distribution range (Campton and Gall 1988). Alternatively, higher predation on larger mosquitofish may be due to a greater detectability by $D$. esakii, as larger fishes produce stronger vibration, e.g., when surfacing (Plath et al. 2011).

Only a non-significant tendency towards male-biased predation was uncovered but only in our binary choice tests (question 2). By contrast, a strong signal of male-biased predation was uncovered in a study on predation by B. cf. bakeri on P. mexicana in a hydrogen sulfide-rich cave (Tobler et al. 2008). The authors reported on higher oxygen demands of male fish leading to more aquatic surface respiration under hypoxic conditions, thus exposing males to elevated levels of predation risk. Moreover, male poeciliid fishes are more active than females, frequently switching between shoals in search of females (Andreev 1994; Griffiths and Magurran 1998; Magurran 1998), again increasing the likelihood of detection by predators. Even though Cech et al. (1985) noted that sex had little effect on metabolic rates when determining oxygen consumption rates of G. affinis in flow-through respirometry chambers while controlling for body mass differences, mate searching, and mating behavior of $G$. affinis males in our binary choice experiment could still result in slightly higher oxygen consumption and occasional aquatic surface respiration, or it simply renders males more detectible and thus vulnerable to predation by $D$. esakii. Slightly male-biased predation could be responsible for the observed female-biased sex ratio of our study population of G. affinis (see also Hildebrand 1927).

In our no-choice experiment, we used the full range of body sizes of $D$. esakii encountered at our study site $(12.44 \pm 3.32 \mathrm{~mm})$, and large-bodied heteropterans were more likely to prey upon G. affinis (question 3). By contrast, only large-bodied, adult heteropterans $(16.19 \pm 0.76 \mathrm{~mm})$ were used in the binary choice experiment, and we did not find the same effect. We argue that predatory strategies and/or energetic demands of $D$. esakii may change during ontogeny. Cloarec (1990) studied predatory tactics adopted by Diplonychus indicus during different developmental stages (see also Ohba and Nakasuji 2006 for Lethocerus deyrolli). Overall, predation success increased with age, and one type of predatory behavior ('lunge', the sudden acceleration from an ambush spot with one stroke of the swimming legs) decreased with age, while another hunting strategy became more frequent ('strike', involving the closing of the claws with or without projection of the forelegs). It seems reasonable to assume that small-bodied D. esakii also adopted the active (lunge) strategy, 
which may render them less efficient fish predators. Venkatesan and Muthukrishnan (1987) reported that earlier instar stages of Diplonychus indicus showed lower assimilation rates when feeding on fish fingerlings compared to tests in which Culex and Aedes larvae were offered. Moreover, life spans of nymphs were lowest when specimens were only provided with fish fingerlings. We argue that large-bodied $D$. esakii likely face a higher risk of being detected by their prey; hence, employing the 'lunge' strategy would lead to considerable energy losses at a comparably low net energy uptake (i.e., successful capture rate). This ought to favor the use of the 'strike' strategy, which is more likely to be successful when preying on fish. Note that D. esakii that were used in the binary choice experiment were uniformly large (adult) individuals, and a "reversed" body size effect within the much smaller body size range was detected. Thus, the possibility remains that aging results in lower metabolic rates and translates into reduced predatory behavior (Biesmeijer and Tóth 1998). Moreover, senescence can be associated with loss of muscle mass and deterioration of neural functioning (Rose 1991; Boggs 2009), possibly impeding predatory behavior of older D. esakii.

Suares and Ramadoss (2003) reported that both nymphs and females of the congeneric Diplonychus rusticus preferred (largely sessile) Chironomus spp. larvae as prey, while male D. rusticus mainly preyed on (actively moving) Culex quinquefasciatus larvae, likely reflecting higher encounter rates with C. quinquefasciatus and a more elaborate predatory behavior in males. A pattern of sex-specific prey choice did not become apparent in our present study (i.e., at least those individuals we could unequivocally identify as males, as they were carrying clutches on their backs, did not show different patterns of prey selection). Several studies on Belostoma flumineum showed that brooding an egg raft increased drag during swimming (Crowl and Alexander 1989; Kight et al. 1995). This cost of paternal care not only impaired the predation efficiency of B. flumineum, but also their agility during escape behavior. In our present study, however, we found no effect of 'presence of eggs' (see "Results"). Based on the argumentation outlined above, D. esakii that showed predation in our experiments may adopt a 'strike' strategy, and so their swimming ability likely had a negligible effect on capture success.

Species become invasive if they establish self-sustaining populations in a new range; however, native faunal elements can slow down this process or even prevent it altogether (Babbitt and Jordan 1996; Locke et al. 2014). For example, Cabrera-Guzmán et al. (2015) found that although invasive cane toads (Rhinella marina) contain potent defensive chemicals, native rodents (Melomys burtoni, Rattus colletti, and R. tunneyi) readily killed and consumed cane toads. Weerman et al. (2014) discovered that spat of invasive Pacific oyster (Crassostrea gigas) is more susceptible to predation by indigenous brown shrimps (Crangon crangon) compared to the spat of native bivalves. In the latter examples, native predators potentially constrain the invasion success or exotic prey species, and we argue that our present study-in conjunction with future studies on other potential predators of G. affinis - may help understand how local predator communities affect the further spread of the species.

Acknowledgements We are grateful to Ke Changsen for accommodation at the Aquaculture Demonstration Station in Ankang. Financial support came from Northwest Agriculture and Forestry University (Z111021403).

Open Access This article is distributed under the terms of the Creative Commons Attribution 4.0 International License (http:// creativecommons.org/licenses/by/4.0/), which permits unrestricted use, distribution, and reproduction in any medium, provided you give appropriate credit to the original author(s) and the source, provide a link to the Creative Commons license, and indicate if changes were made.

\section{References}

Andreev OA (1994) The behavior of male and female guppies in an unfamiliar environment. J Ichthyol 34:139-143

Babbitt K, Jordan F (1996) Predation on Bufo terrestris tadpoles: effects of cover and predator identity. Copeia 2:485-488

Bailey PCE (1986) The feeding behaviour of a sit-and-wait predator, Ranatra dispar (Heteroptera: Nepidae): description of behavioural components of prey capture, and the effect of food deprivation on predator arousal and capture dynamics. Behaviour 97(1):66-92

Biesmeijer JC, Tóth E (1998) Individual foraging, activity level and longevity in the stingless bee Melipona beecheii in Costa Rica (Hymenoptera, Apidae, Aeliponinae). Insectes Soc 45(4):427-443

Błońska D, Grabowska J, Kobak J, Jermacz Ł, Bącela-Spychalska K (2015) Feeding preferences of an invasive Ponto-Caspian goby for native and non-native gammarid prey. Freshw Biol 7:1-9. doi:10.1111/fwb.12647

Boggs CL (2009) Understanding insect life histories and senescence through a resource allocation lens. Funct Ecol 23(1):27-37 
Cabrera-Guzmán E, Crossland MR, Pearson D, Webb JK, Shine R (2015) Predation on invasive cane toads (Rhinella marina) by native Australian rodents. J Pest Sci 88:143-153. doi:10.1007/s10340-014-0586-2

Campton DE, Gall GAE (1988) Responses to selection for body size and age at sexual maturity in the mosquitofish, Gambusia affinis. Aquaculture 68(3):221-241

Carlsson NOL, Sarnelle O, Strayer DL (2009) Native predators and exotic prey—an acquired taste? Front Ecol Eviron 7(10):525-532

Cech JJJr, Massingill MJ, Vondracek B, Linden AL (1985) Respiratory metabolism of mosquitofish, Gambusia affinis: effects of temperature, dissolved oxygen, and sex difference. Environ Biol Fish 13(4):297-307

Chen GZ (2010) Interspecific relationship between the invasive species Gambusia affinis and the native endangered species Tanichthys albonubes. Dissertation, Jinan University

Chen YR, Yu HH, Chu XL (1989) Taxonomy and distribution of the genus Oryzias in Yunnan, China. Acta Zootax Sin 2:239-246

Cloarec A (1990) Variations of predatory tactics of a water bug during development. Ethology 86:33-46

Crowl TA, Alexander E Jr (1989) Parental care and foraging ability in male water bugs (Belostoma flumineum). Can J Zool 67:513-515

Cullen MJ (1969) The biology of giant water bugs (Hemiptera: Belostomatidae) in Trinidad. Proc R Ent Soc Lond 44:123-136

David P, Thébault E, Anneville O, Duyck PF, Chapuis E, Loeuille N (2017) Impacts of invasive species on food webs: a review of empirical data. Adv Ecol Res 56:1-60

Ding JH (2004) The taxonomic study on some families of aquatic Heteroptera from China. Dissertation, Nankai University

Gerard A, Jourdan H, Cugniere C, Millon A, Vidal E (2014) Is naïveté forever? Alien predator and aggressor recognition by two endemic island reptiles. Naturwiss 101(11):921-927. doi:10.1007/s00114-014-1233-8

Godin JGJ (1995) Predation risk and alternative mating tactics in male Trinidadian guppies (Poecilia reticulata). Oecologia 103(2):224-229

Griffiths SW, Magurran AE (1998) Sex and schooling behaviour in Trinidadian guppies. Anim Behav 56:689-693

Gurevitch J, Padilla DK (2004) Are invasive species a major cause of extinctions? Trends Ecol Evol 19:470-474

Harak M, Kuusik A, Hiiesaar K, Metspalu L, Luik A, Tartes U (1998) Calorimetric investigations on physiological stress in Tenebrio molitor (Coleoptera, Tenebrionidae) pupae. Thermochim Acta 309(1-2):57-61

Hazarika R, Goswami MM (2012) Feeding behavior of Diplonychus rusticus Fabricius (Hemiptera, Belostomatidae) on fish and fish food. Int Proc Chem Biol Environ 40:136-140

Hildebrand SF (1927) Sex ratio in Gambusia. Biol Bull 53(5):390-404

Horstkotte J, Plath M (2008) Divergent evolution of feeding substrate preferences in a phylogenetically young species flock of pupfish (Cyprinodon spp.). Naturwiss 95(12):1175-1180. doi:10.1007/s00114-008-0439-z

Jourdan J, Bierbach D, Riesch R, Schieß1 A, Wigh A, Arias-Rodriguez L, Indy JR, Klaus S, Zimmer C, Plath M (2014) Microhabitat use, population densities, and size distributions of sulfur cave-dwelling Poecilia mexicana. PeerJ 2:e490. doi:10.7717/peerj.490

Kight SL, Sprague J, Kruse KC, Johnson L (1995) Are egg-bearing male water bugs, Belostoma flumineum Say (Hemiptera: Belostomatidae), impaired swimmers? J Kans Entomol Soc 68(4):468-470

Kistner EJ, Dybdahl MF (2013) Adaptive responses and invasion: the role of plasticity and evolution in snail shell morphology. Ecol Evol 3(2):424-436. doi:10.1002/ece3.471

Li ZY, Xie Y (2002) Invasive species in China. China Forestry Publishing House, Beijing, p 88

Locke SA, Bulté G, Marcogliese DJ, Forbes MR (2014) Altered trophic pathway and parasitism in a native predator (Lepomis gibbosus) feeding on introduced prey (Dreissena polymorpha). Oecologia 175:315-324. doi:10.1007/s00442-014-2898-6

Magurran AE (1998) Population differentiation without speciation. Philos Trans Roy Soc Lond B 353:275-286

Menke A (1979) Family Belostomatidae_giant water bugs. The semiaquatic and aquatic hemiptera of California (Heteroptera: Hemiptera). University of California Press, Berkeley, pp 76-86

Miyamoto S, Lee CE (1966) Heteroptera of Quelpart Island (Chejudo). Sieboldia 3:313-426

Mori A, Ohba S (2004) Field observations of predation on snakes by the giant water bug. Bull Herpetol Soc Japan 2004:78-81

Mukherjee B, Datta NC (1999) New biological control agents of mosquito. Environ Ecol 17(3):622-625

Nunes AL, Orizaola G, Laurila A, Rebelo R (2014) Rapid evolution of constitutive and inducible defenses against an invasive predator. Ecology 95(6):1520-1530

Ohba S (2011) Field observation of predation on a turtle by a giant water bug. Entomol Sci 14(3):364-365. doi:10.1111/j.14798298.2011.00450.x

Ohba S, Nakasuji F (2006) Dietary items of predacious aquatic bugs (Nepoidea: Heteroptera) in Japanese wetlands. Limnology 7:41-43. doi:10.1007/s10201-006-0161-5

Plath M, Tobler M (2010) Subterranean fishes of Mexico (Poecilia mexicana, Poeciliidae). In: Trajano E, Bichuette ME, Kapoor BG (eds) Biology of subterranean fishes. Science Publishers, Taylor \& Francis Inc, Enfield, pp 281-330

Plath M, Parzefall J, Schlupp I (2003) The role of sexual harassment in cave and surface dwelling populations of the Atlantic molly, Poecilia mexicana (Poeciliidae, Teleostei). Behav Ecol Sociobiol 54(3):303-309. doi:10.1007/s00265-003-0625-0

Plath M, Tobler M, Riesch R, de Leon FJG, Giere O, Schlupp I (2007) Survival in an extreme habitat: the roles of behaviour and energy limitation. Naturwiss 94(12):991-996. doi:10.1007/s00114-007-0279-2

Plath M, Riesch R, Culumber ZW, Streit B, Tobler CM (2011) Giant water bug (Belostoma sp.) predation on a cavefish (Poecilia mexicana): effects of female body size and gestational state. Evol Ecol Res 13:133-144

Pyke GH (1984) Optimal foraging theory-a critical review. Annu Rev Ecol Syst 15:523-575

Rao TKR (1976) Bioecological studies on some aquatic Hemiptera-Nepidae. Entomon 1:123-132

Raspi A, Abdimaleki R, Fallahzadeh M, Saghaei N, Benelli G (2015) The Oriental drosophilid Cacoxenus (Gitonides) campsiphallus, a predator of invasive mealybugs: first record for Palearctic region and female's description. J Asia-Pac Entomol 18(3):525-528 
Reznick D (1981) "Grandfather effects": the genetics of interpopulation differences in offspring size in the mosquito fish. Evolution 35(5):941-953

Rose MR (1991) Evolutionary biology of aging. Oxford University Press, New York

Saha N, Aditya G, Saha GK, Hampton SE (2010) Opportunistic foraging by heteropteran mosquito predators. Aquat Ecol 44(1):167-176

Saha N, Aditya G, Saha GK (2014) Prey preferences of aquatic insects: potential implications for the regulation of wetland mosquitoes. Med Vet Entomol 1(28):1-9

Schumann DA, Cavallaro MC, Hoback WW (2012) Size selective predation by Hydrophilis triangularis (Coleoptera: Hydrophilidae) and Lethocerus americanus (Hemiptera: Belostomatidae). J Kansas Entomol Soc 85(2):155-159

Stephens DW, Brown JS, Ydenberg RC (2007) Foraging: behavior and ecology. University of Chicago Press, Chicago

Stuart YE, Campbell TS, Hohenlohe PA, Reynolds RG, Revell LJ, Losos JB (2014) Rapid evolution of a native species following invasion by a congener. Science 346:463-466. doi:10.1126/science.1257008

Suares MC, Ramadoss R (2003) Predatory strategy of the water bug, Diplonychus rusticus Fabr. (Heteroptera: Belostomatidae) through their immature stages and adulthood. J Entomol Res 27(3):189-195

Swart CC, Felgenhauer BE (2003) Structure and function of the mouthparts and salivary gland complex of the giant waterbug, Belostoma lutarium (Stål) (Hemiptera: Belostomatidae). Ann Entomol Soc Am 96(6):870-882. doi:10.1603/00138746(2003)096[0870:SAFOTM]2.0.CO;2

Swart CC, Deaton LE, Felgenhauer BE (2006) The salivary gland and salivary enzymes of the giant waterbugs (Heteroptera; Belostomatidae). Comp Biochem Phys 145(1):114-122. doi:10.1016/j.cbpa.2006.05.010

Tobler M, Schlupp I, Plath M (2007) Predation of a cave fish (Poecilia mexicana, Poeciliidae) by a giant water-bug (Belostoma, Belostomatidae) in a Mexican sulphur cave. Ecol Entomol 32(5):492-495. doi:10.1111/j.1365-2311.2007.00892.x

Tobler M, Franssen C, Plath M (2008) Male-biased predation on a cave fish by a giant water bug. Naturwiss 95:775-779

Tobler M, Riesch RW, Tobler CM, Plath M (2009) Compensatory behaviour in response to sulphide-induced hypoxia affects time budgets, feeding efficiency, and predation risk. Evol Ecol Res 11:935-948

Tobler M, Roach K, Winemiller KO, Morehouse RL, Plath M (2013) Population structure, habitat use, and diet of giant waterbugs in a sulfidic cave. Southw Nat 58:420-426

Venkatesan P, Muthukrishnan S (1987) Impact of predation and food utilization on reproduction of Diplonychus indicus, and Danatra filiformis. Proc Anim Sci 96(3):293-304

Weerman EJ, Eriksson BK, Olff H, van der Heide T (2014) Predation by native brown shrimp on invasive Pacific oyster spat. J Sea Res 85:126-130. doi:10.1016/j.seares.2013.04.010 